\title{
DIVAGACIONES SOBRE EL GRABADO
}

\author{
POR \\ CARLOS PALOMAR
}

\begin{abstract}
A LUIS BARRAGAN, cuya sngestión a responsable de estas bagatelas y cuya devoción a los primitivos comparte, si no es que tupera, in amigo afectítimo.
\end{abstract}

\section{PARA EMPEZAR}

DESDE tiempo inmemorial soy un ferviente aficionado a los grabados. Creo que si me hubiera tocado en suerte disfrutar de una gran fortuna, habría empleado una buena parte de ella en coleccionar estampas originales, las cuales tengo que limitarme a admirar en reproducciones más - menos bien logradas.

Ese gusto por el grabado, que estoy por decir que es mayor que el que siento por la pintura, se debe quizás a que ésta me es menos comprensible, pues no tengo ojo de colorista. De haber sido pintor, de seguro no me hubiera podido formar en la escuela del Ticiano o de Monet, para no citar sino dos de los más grandes maestros del color del Renacimiento y de los tiempos modernos. 
El grabado, cuya historia es la de la humanidad, 1 me parece hasta cierto punto más creativo, más individual, más propicio a la estilización, que la pintura. Dentro de sus limitaciones, comprende todo un mundo de aventuras de la linea, que se erige en soberana y adquiere vida propia por la fuerza de expresión de que es susceptible. Su belleza, o su sugerencia, se impone a nuestro sensorio dentro de la página en que se imprime el grabado, la cual, a la vez que to limita, to hace adquirir una universalidad insospechada. Más bien que los objetos que representa, hemos de considerar una arquitectura lineal cuyos elementos fueran las salidas de la madera, los surcos del buril o las mordidas del ácido (según el método empleado). y que uniéndose entre sí, separándose, yuxtaponiéndose, formarían la obra de arte.

Casi pudiera evitar el decir que no abrigo ilusión alguna sobre el valor de estas cortas "divagaciones"; pero si se me preguntara qué es lo que me ha animado a escribirlas, a mí que no entiendo nada de grabado y jamás he visto hacer ninguno, diré lo siguiente: En su libro sobre "Etching", el famoso grabador Pennell, al hablar de la plancha de Dürer "El cañón", en la misma página asegura que es un grabado directo (engraving); luego afirma que es aguafuerte (etching); después manifiesta que hay muchas opiniones $y$, por fin, agrega dos notas que acaban de dejar perplejo al lector. Si un maestro de la talla de ese americano confiesa sus dudas en la forma expresada respecto de una obra célebre, me considero autorizado para tomar la pluma y escribir a mi gusto algunos dislates más sobre un arte que tanto quiero.

\section{LO QUE EL GRABADO DEBE SER}

Se lee en el libro de Thomas Craven "Men of Art", que no existe razón alguna para hacer aguas fuertes, ya que el mismo efecto se logra por medio de un dibujo a pluma. El agua fuerte, según él, es el procedimiento rebuscado y laborioso de rasear un pedazo de cobre tiznado. Sólo encuentran gracia a sus ojos las aguas fuertes de Rembrandt por la extraña razón de que éstas rivalizan con el alcance y poder de la pintura.

i Estamos lucidos! Poco falta a Mr. Craven para decir: " $\mathrm{i}$ Los'grabados de Rembrandt son admirables porque difieren lo más posible de lo

1 F. Esteve Botey. Historia del Grabado. (Colección Labor.) 
que debe ser un grabado!" Olvida el autor que el grabado es un medio de expresión destinado a ejemplares FUNCIONAI,MENTE, es decir, con absoluto respeto al procedimiento empleado. En otros términos, una litografia debe parecer litografia, y no un dibujo a lápiz Conté ; una punta seca tiene que mirarse formada de rasgos de buril sobre cobre y no tratar de competir con dibujos a pluma, $y$ asi sucesivamente.

¡Cuánto más sabio es el consejo de Ruskin!: "Sea cual fuere el material que tú escojas para trabajar, tu arte será vil si no expone y desarrolla las cualidades distintivas de ese material."

III. LO QUE EL GRABADO NO DEBE SER

Luis Dimier en la introducción a su obra "La Gravure" se permite decretar que todos aquellos que no quieran aprobar más que las obras originales, abandonen la historia del grabado. Dice que la mitad de los grabadores se han hecho célebres copiando obras de pintura, $y$ que en fin de cuentas el grabado es una falsificación del dibujo.

Nos parece que este señor está completamente equivocado. Puede uno hasta la saciedad tener admiración por las habilidades de los grabadores que reproducen; pero asi se llamen éstos Bartolozzi o Gaillard, no desarrollan una actividad creativa, $y$ creemos injusto que se les incluya en el mismo cuadro que a un Rembrandt o un Goya.

Sostenemos que el grabado tiene su razón de ser en si mismo, y que no está destinado a ser un simple auxiliar o propagador de la pintura ni de ninguna otra actividad artística, por más que en el pasado haya prestado en ese sentido (cuando no existian los sistemas modernos de reproducción) servicios muy meritorios.

Ya expresamos en el anterior párrafo nuestra opinión, que podría reducirse a esta fórmula aparentemente perogrullesca: "el grabado es el grabado". Una plancha para imprimir, en general, se llama grabado; pero el grabado debe emplearla como fin y no como medio. $O$ si se quiere: el grabado tiene que ser amo y no criado, señor de su propio dominio y no lacayo de otras artes. Si el grabador se considera incapaz de crear directamente sobre la placa o la madera, que se limite a dibujar sobre el papel, pues ya encontraremos la manera de reproducir sus dibujos; i pero entonces que se nos permita quitarle el nombre de grabador! 


\section{EJ ENCANTo PECULIAR de LOS ANTIGUOS}

He aquí una serie de grabados en madera o en "criblè", destinados, en su gran mayoría, a la ilustración de los primeros libros. No pueden luchar en primor técnico con las ilustraciones iluminadas de los manusctitos, a pesar de que a veces están coloreados a mano (lo sual les resta valor, a mi entender).

Despojémonos de la cáscara civilizada y cientifica de la vida moderna $y$ observemos con ojos primitivos estas creaciones de almas infantiles $y$ creyentes. Veamos cómo resuelven los problemas de interpretación del triverso exterior, transformándolo en el mundo nuevo de la plancha grahada. Danzas de la muerte, escenas bíblicas, tipos populares, vidas de santos...

Todo ello observado dentro de una perspectiva plana, si se me permite la expresión absurda; pero que en cambio logra una distribución lógìca y equilibrada dentro del contorno que encierra la estampa. Si hubiéremos de buscar un vocablo para designar la cualidad caracteristica de estas imágenes, diríamos que son, en grado superlativo, tipográficas.

Gocemos con los detalles: el agua que corre en torno de las piernas de San Cristóbal, representada por medio de una serie paralela de líneas onduladas; los pliegues de los vestidos, rígidos pero decorativos, distrihuyéndose en deliciosas simetrias; las miradas del espiritu maligno, en fornia de rayos divergentes; las muecas de espanto y de dolor de los moribundos y de los réprobos; la serenidad del rostro de la Virgen... y teintos ofros que seria prolijo enumerar.

En el tiempo presente, en que nuestra percepción estética, enferma de realismo, ha reaccionado, para apreciar sobre todo las cualidades de la obra de arte en sí misma, con preferencia a sus caracteristicas representacionales - Io que podriamos llamar criterio expresionista-, es natural que disfrutemos con mayor fruición de los grabados antiguos, cuya organización plástica y percepción directa e ingenua de la realidad, los hacen tan superiores a los alardes técnicos de las reproducciones pretendidamente fotográficas del mundo visible.

\section{v. NOTAS SOBRE ALGUNOS GRABADORES}

Los diez grabadores que he escogido, figuran aqui por razones históricas, artísticas o simplemente personales, $y$ seria inútil enumerarlas todas. 
No quiere decir esto que los artistas incluídos sean los más grandes que el grabado haya producido, y desde luego se omiten los contemporáneos y los grabadores del Extremo Oriente.

Por no hacer muy largo este estudio, no se hace mención del gran Lucas van Leyden, en quien se aúnan las mejores cualidades de las escuelas italiana y germánica; del desconocido que firmaba sus preciosidades decorativas con las iniciales E. S.; de los grabados en camaieu del extraño Hans Burgkmair; de las detalladisimas imágenes de Albrecht Altdorfer; del esprit y variedad de Lucas Cranach; de la imaginación de Hans Baldung Grien; de la sobriedad de Hans Seebald Beham; de las ilustraciones de libros de Jost Amman; de las escenas de guerra de Urs Graf y de Peter Flöttner ; de las prestigiosas realizaciones de Martin Schöngauer, y de tantos otros grabadores, sobre todo aquéllos que, durante los siglos XV y Xvi, hicieron de Alemania la tierra de promisión de este arte.

En cuanto a Italia, nos hemos conformado con citar al Parmesano, y lamentamos no decir nada de las figuras de santos de Guercino, de la forma escultórica de Mantegna, de los jinetes de Stefano della Bella, de las prisiones de pesadilla de Piranesi, de los dramáticos paisajes de Salvator Rosa y de la brillantez del decorador Tiepolo.

No acabaríamos nunca si citáramos a Rubens y Van Dijck, éste con sus inigualables retratos; al digno sucesor de Daumier, Jean Louis Forain ; al inglés Brangwyn; al noruego Zorn; al belga Rops, y a Lalanne, Legros, Bracquemond, Fantin-Latour, Toulouse Lautrec, Seymour Haden, Muirhead Bone... sin hablar del extraordinario renacimiento del grabado en madera que se ha suscitado en nuestro tiempo en Francia y en otros lugares.

\section{1. $D \ddot{U} R E R$}

Si alguien ha merecido que se le ponga como apellido el de "Grabador", es seguramente Dürer, cuya obra nos aparece como una verdadera enciclopedia del arte $\mathrm{y}$ del saber de su tiempo.

Al contemplar, atónitos, sus series de aguas fuertes y de maderas, no podemos menos de preguntarnos de dónde pudo haber sacado tanto tiempo para ese titánico trabajo, sobre todo si se tiene en cuenta que tuvo la mala suerte de casarse con una harpia insufrible.

Su obra tiene un incomparable acabado, y detalles casi increíbles. A veces hasta quisiéramos que dejara un poco suelta la rienda a nuestra imaginación y sugitiera alguna imagen a la fantasía de los espectadores, ya que él no omite nada en sus obras. Pero también ese derroche de deta- 
lles, que hace que los conjuritos desmerezcan a veces un poco, unido a cierta ingenuidad netamente germánica, alguna rigidez en las texturas y draperías y algo de primitivismo en la perspectiva, nos hacen concebir por su obra un nuevo entusiasmo, pues ya sabemos que el alma moderna está enamorada de lo primitivo. Sin duda no amariamos tanto a Dürer si hubiera vivido un siglo después.

Si alguna frase pudiera caracterizar el genio de Dürer, yo escogeria ésta: "el apoteosis de la linea".

(Albrecht Dürer, 1471-1528.)

\section{HOLBEI N}

Sus viñetas de la Danza Macabra forman una universal baraja con la que se jugara la suerte del género humano. i $\mathbf{Y}$ cómo se divierte la Muerte con los pobres mortales! A algunos se los lleva riendo a carcajadas, y a otros, en sus ratos de mal humor, se entretiene en hacerlos stafrir. ¿Qué le importa?

He aquí unos grabados en madera de una caracterización extraordinaria. Han dado forma definitiva a las Danzas de la Muerte que tan populares fueron en la Edad Media. Esa serie de miniaturas, unidas a las ilustraciones biblicas de Holbein, son para el artista un timbre de gloria comparable a sus admirables retratos al óleo. Campea en sus maderas una distinción superior a la de Dürer, juntamente con una ciencia muy grande de la forma y una mise en page en verdad excepcional.

(Hans Holbein der Jüngere, 1497-1543.)

\section{EL PAR M S A NO.}

En Italia fué el Parmesano, si no el primero, uno de los primeros en emplear el procedimiento del agua fuerte. Tuvo la atingencia de usarlo para bocetos; y eso, que para sus contemporáneos, amantes de lo acabado de la forma, lo hizo pasar poco menos que inadvertido, en cambio en nuestros tiempos lo ha hecho cada vez más apreciado, por lo cercano que está a nuestro espíritu.

Sus obras, realzadas a veces con algo de blanco o con colores, pertenecen a la escuela del Correggio, y por ende se halla en eilas lo "siumato" de los contornos, y épor qué no decirlo? a veces un poquitín de afectación. 
Pero no por eso dejan de ser verdaderamente deliciosas, y es de sentirse que se conozca tan poco número de ellas.

(Girolamo Francesco Maria Mazzouli, iL parmigiano, 1503-1540.)

\section{4. $C A L I O T$}

¿Quién ha tenido en ese grado superlativo el dón de la composición? ¿Quién ha sabido agrupar de esa manera magistral tan enorme cantidad de figuritas de soldados, de cortesanos, de campesinos o de mendigos?

Una de las horas más agradables de toda mi vida, la pasé en el Gabinete de Estampas del Museo Metropolitano de Nueva York, cuando solicité se me enseñaran algunos grabados de Callot. ¡Cuál no sería mi sorpresa al ver que se me traian cientos y cientos de ellos, perfectamente presentados y encuadernados! Alli me convenci de que ninguna reproducción puede dar idea de la inaudita finura de grabado de esas obras.

A medida que el tiempo pasa, la figura de Callot se agiganta. Ante el criterio artistico moderno aparecen sus grabados como una continua serie de aciertos de adecuación funcional de elementos plásticos. Sus obras tienen unidad orgánica, verdadera monumentalidad dentro de sus pequeñas dimensiones, visión variadisima de las ferias italianas y de las miserias de la guerra.

El empleo del barniz duro, que adoptó Callot, da a sus trazos una delicadeza sin par. Casi nunca se encuentran en sus obras los trazos cruzados, y sus efectos se logran con una gran economía de líneas.

Pocos goces habrá en el mundo mayores que el de examinar las amenisimas creaciones de Callot.

(Jacques Callot, 1592-1635.)

\section{RE $\triangle B R A N D T$}

Para mi, Rembrandt es el artista plástico por excelencia, y ocupa en la historia de las artes visuales un lugar de la misma categoría que el de Bach en la música y el de Shakespeare en la literatura.

Su grandeza aparece lo mismo en un óleo de grandes dimensiones que en un pequeño dibujo que hiciera sobre el suelo con una caña mojada en lodo. Reflexionando sobre su obra, podría edificarse todo un sistema filosófico, sobre la base de una profunda confraternidad universal. Una extraordinaria luz, emanada de las profundidades de su alma, ilumina sus 
creaciones, infundiéndoles una vida inmortal. I $\mathrm{Y}$ qué universalidad! Desde los buenos burgueses de Amsterdam orgullosos de su opulencia, hasta el molino natal; desde la sinagoga hasta los campesinos en escenas francamente rabelesianas, $y$ desde los arbolillos de la campiña holandesa hasta la conmovedora figura de Nuestro Señor, que ningún pintor ha logrado nunca representar de un modo más evangélico, todo se halla en Rembrandt en un grado incomparable.

- Si, pero Rembrandt es teatral -dice Nacho Diaz Morales- prefiero al Greco.

- Rembrandt es teatral, si ; pero en el sentido de que la vida es un teatro, en el que todos tenemos que representar nuestro papel. El Greco es aún más teatral. ¿ No es "El entierro del Conde de Orgaz" un verdadero ballet? Ballet eclesiástico, se dirá; pero ballet al fin.

Unas palabras sobre los grabados de Rembrandt a que ya hemos aludido con anterioridad.

EI agua fuerte tiene aquí su culminación, a veces con un olimpico desdén hacia todas las reglas que los acuafortistas han elaborado. Ciertas planchas son verdaderos cuadros, con colorido y todo. Otras emiten radiciones de una intensidad expresiva que sólo puede comprenderse absorbiéndose indefinidamente en su contemplación. El retrato de la madre del artista mide sólo uno o dos centímetros: hay aquí más arte que en algunos kilómetros cuadrados de pinturas murales.

(Rembrandt Hermenszoon van Rijn, 1609-1669.)

\section{GOYA}

Un intelecto artístico único en su tiempo; un formidable intérprete de la podrida sociedad en que vivió; un hombre, en toda la extensión de la palabra.

Hagamos caso omiso de la técnica, que Goya trata con un soberano desprecio. No nos fijemos en la composición, que si a veces es incomparable, en ocasiones no tiene pies ni cabeza. Olvidemos toda consideración artística y sólo ocupémonos de idēntificarnos por completo con esta humanidad tan profunda, tan descarnada, tan patética. Volemos en las alas de esa fantasía en ebullición y asombrémonos de los caprichos y DISPARATES de esa mente excepcional, creadora de fantasmas y monstruos; pero al mismo tiempo, en suS DESASTRES DE LA GUERRA, exponente supremo de la realidad dentro de la más tremenda condensación del dolor humano.

(Francisco de Goya y Lucientes, 1746-1828.) 


\section{DAU MIER}

El arte es una deformación. Todo artista convierte la realidad exterior (o su realidad subjetiva) en formas y colores que, evidentemente, nadie pretende sean iguales a la naturaleza.

Pero unos pintan deformando hacia lo "bonito" como un Bouguereau, mientras que otros tienden a exagerar la fealdad: a éstos se les llama caricaturistas. De todos modos, habiendo la deformación de que se ha hablado, podemos decir, que si la caricatura es arte, el arte es caricatura, quitando a esta palabra toda connotación despectiva.

Daumier es el más grande de los caricaturistas y también uno de los más grandes artistas que han existido. Sus dotes de observación, que parece que estructuran de nuevo para nosotros la figura humana, se combinan con un sentido segurísimo de armonia plástica, un gran equilibrio expresivo, y una integración intuitiva de las formas y volúmenes dentro del sentimiento y sinceridad más profundos.

Una litografia de Daumier es algo que honra al luchador y fustigador incansable de los vicios humanos; pero igualmente es, por añadidura, una realización artística que deja en el espectador una rara sensación de plenitud $\mathrm{y}$ de unanimidad con el artista.

(Honoré Daumier, 1808-1879.)

\section{M E R Y O N}

Parisiense (de origen inglés, según entiendo), dedicóse principalmente a observar los edificios de la Ciudad Luz, siendo sus aguas fuertes verdaderos documentos históricos a la vez que obras de arte.

Como cronista gráfico de París ha suscitado una verdadera pléyade de grabadores, los cuales no se consideran satisfechos si no han grabado por lo menos una vez el ábside de Notre Dame, posiblemente el lugar del mundo que más ha figurado en planchas de madera, metal o piedra.

Las aguas fuertes de Méryon, no siempre exentas de un poco de rigidez, tienen una gran solidez tectónica; $y$ algunas de ellas, como la alucinante gárgola de la catedral parisiense, no se olvidan jamás una vez vistas.

(Charles Méryon, 1821-1868.)

\section{W H I S T L E R}

Es un poco dificil asignar a Whistler el lugar que le corresponde justamente en la historia del arte, pues mientras que en su vida fué objeto 
de las polémicas más interesantes y quizá más apasionadas que artista alguno haya conocido, en cambio después de su muerte no falta quien lo ponga, en tanto que acuafortista, inmediatamente después de Rembrandt, y hasta se le ha llegado a poner encima de éste, como lo hace Pennell.

No cabe duda que las aguas fuertes de Whistler son de una técnica acabada, de una maravillosa delicadeza de trazo y de una impresión (por el mismo autor) perfecta. Pocos han sabido, como él, comprender las posibilidades del procedimiento, en el que cumple, como nadie, el desiderátum del Tasso:

"L'arte, che tutto fa, nulla si scopre."

Siempre me ha parecido encontrar analogía entre el agua fuerte y la música de cámara. En ambas se triunfa por la restricción, por el substratum, por la sinceridad y por la supresión del efectismo. Si una de esas manifestaciones artísticas sabe pasarse sin el colorido de la pintura, la otra no necesita del colorido orquestal; y en cuanto al virtuosismo que pueda haber en ellas, se le oculta tan cuidadosamente que parece que el éxito se debe sólo a la espontaneidad.

Las planchas de Whistler que forman la serie del Támesis, sobre todo "Rotherhite" y "El muelle del León Negro" sorprenden en verdad por lo ingenioso y lo bien rendido de los detalles. En cambio en la serie de Venecia es el conjunto lo que nos strbyuga: el máximo de stugerencia con el aparente mínimo de medios.

La influencia de Whistler en los grabados modernos ha sido enorme. (James Abbot McNeill Whistler, 1834-1903.)

\section{PEN N EL L}

Grabador por excelencia, Pennell ha usado casi de todos los procedimientos que existen, $y$ ha teorizado sobre ellos en un lenguaje hirsuto $y$ cortante, de los que no consienten contradicciones.

Son notables sus grabados, en que se muestran las múltiples facetas de la vida londinense, y las escenas del tiempo de la guerra en esa capital. Tomó igualmente como motivo de sus planchas varios aspectos de la época industrial moderna, que desarrolla con una técnica impresionista, amplia y sumaria.

Siguió el camino trazado por Whistler, al lado de quien trabajó y por quien profesaba una admiración verdaderamente sin límites.

(Joseph Pennell, 1860-1926.) 


\section{BIBLIOGRAFIA}

Las obtas que a continuación se citan tienen desde luego la ventzja de au precio modesto. La más cara no llega a 3 dollars.

DÚRER.-Complete woodcuts (Ed. br Dr. W. Kartb).

REMBRANDT, Complete etchings.

MASTERPIECES OF ETCHING (2 vols. Cowans \& Gray).

DÚker.-Burins (Encyclopedie Alpina).

REMBRANDT.-Eaux fortes (Id).

Notes ON pRINTs (Metropolitan Museum. N. Y.),

Whistler, par Th. Duret.

JOSEPH PENNELL._-Etchers and Etching.

CAltot.-Estamper de la Bibliothèque Nationale.

L. Dimier, -La Gravure.

F. EsteVE BoteY.-Historia del Grabado (Col. Labor).

THE STUDIO.-Volúmenes sobre los principales maestros del agaa fuerte.

DEUTSCHE HOLZSCHNITTE BIS ZUM ENDE DES XVI. JAHRHUNDERTS (Grabado: ea madera. alemanes, hasta el fin del siglo XVI).

HoLbejN (Ed. Velhagen a. Klassings).

GoYA.-The Disasters of War (Phaidon Press).

DAUMIER,-CPar Raymond Escholier.

CARL Zigrossar.-Six Centuries of Fine Prints. 
DOI: http://dx.doi.org/10.22201/iie.18703062e.1943.10.363
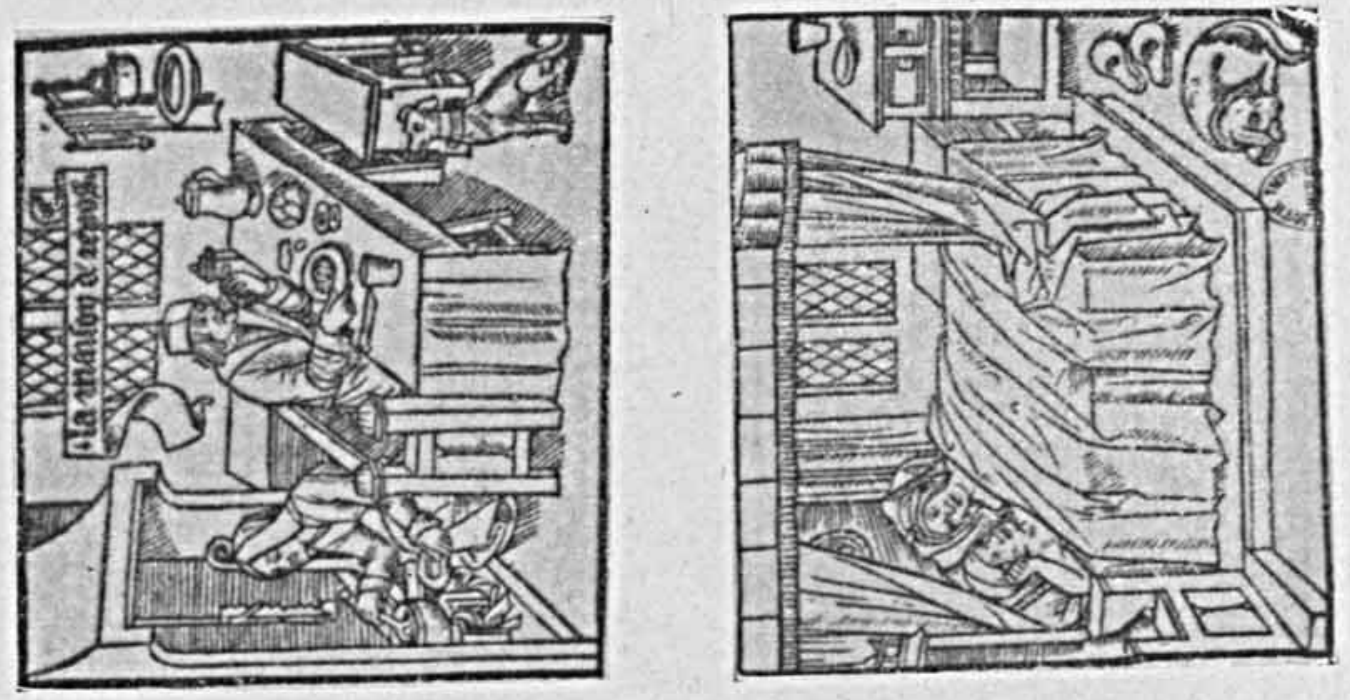

है
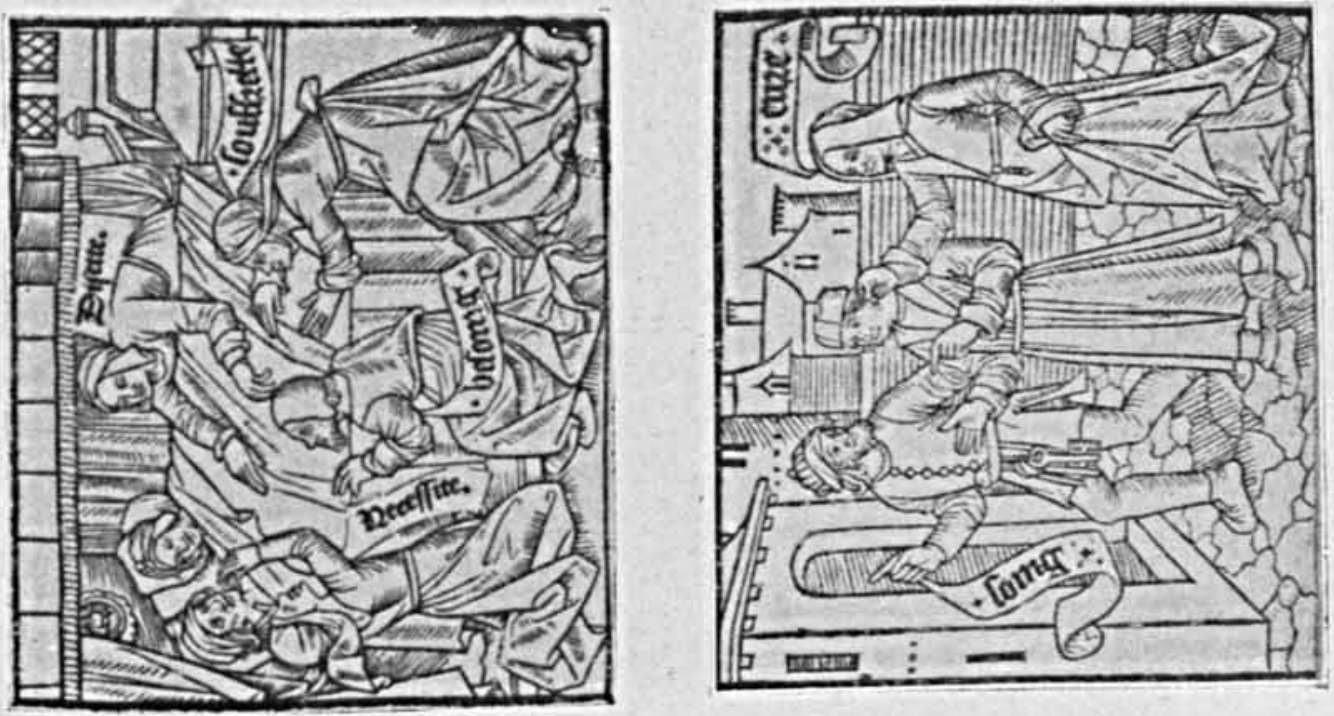


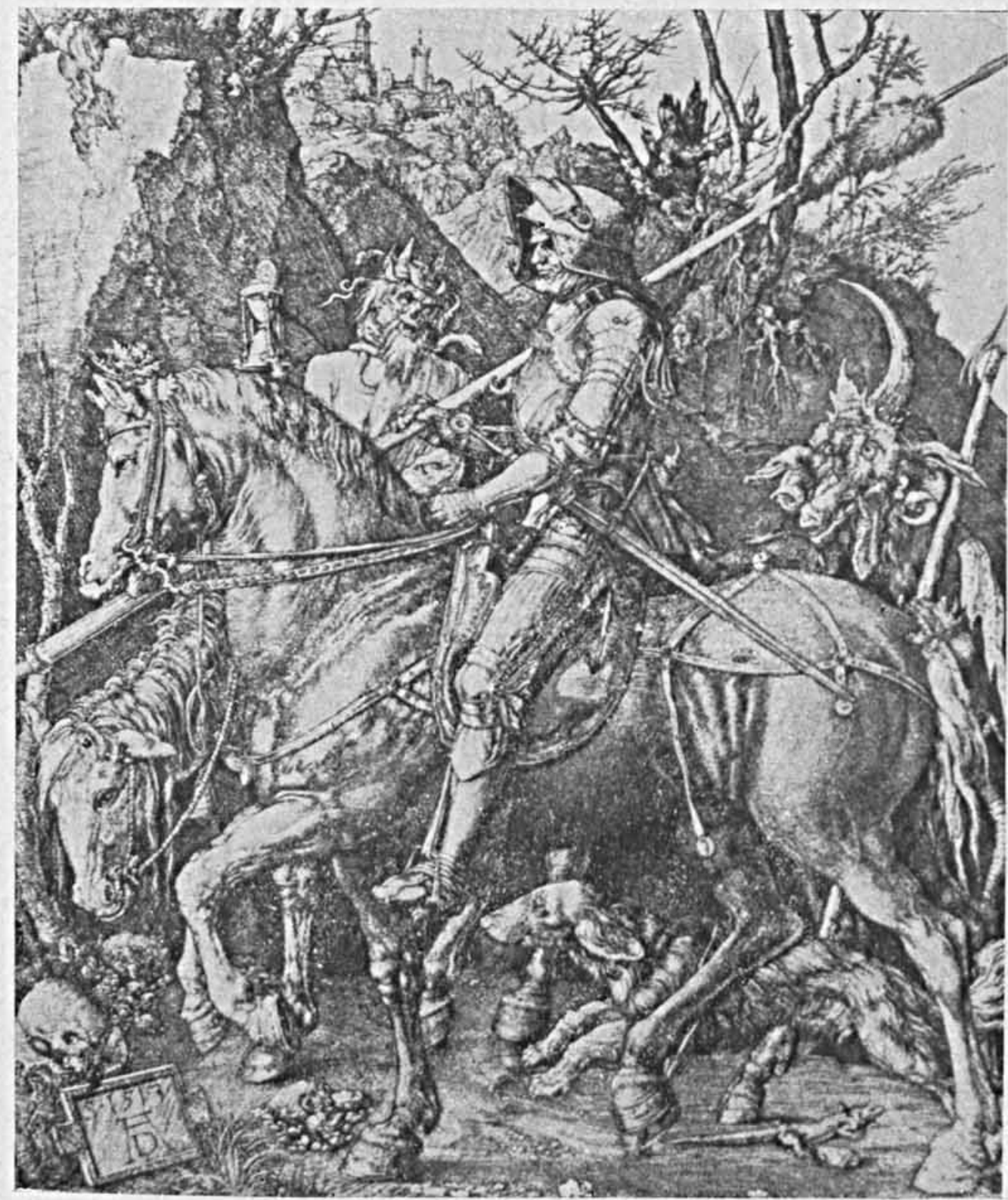

2. Dürer.-El Caballero, la Muerte y el Diablo. 

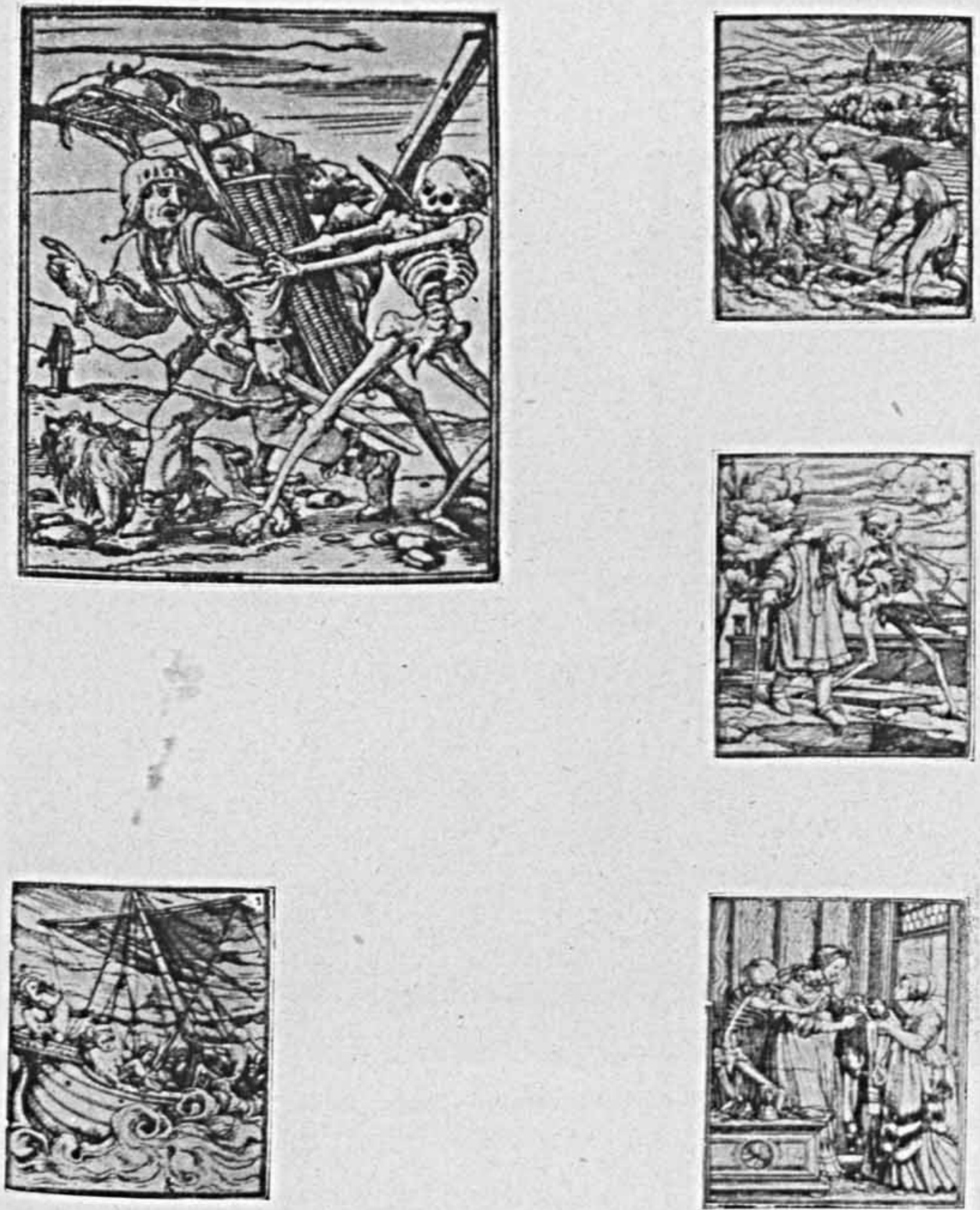

3. Holbein.-La Danza Macabra. (El Buhonero, el Labrador, el Anciano, el Marino, la Condesa.) 
DOI: http://dx.doi.org/10.22201/iie.18703062e.1943.10.363

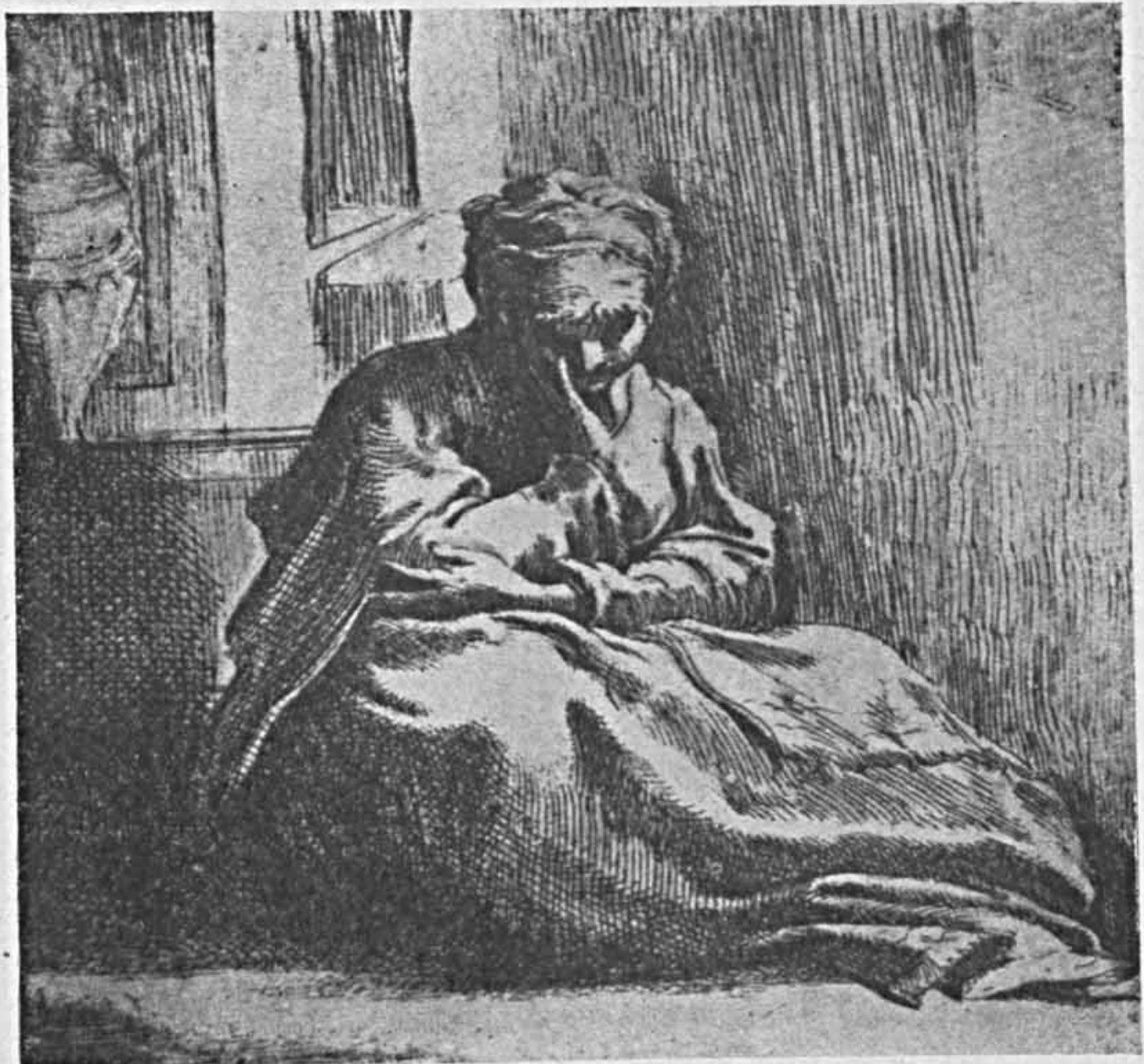

4. El Parmesano.-Santa Taide. 
DOI: http://dx.doi.org/10.22201/iie.18703062e.1943.10.363

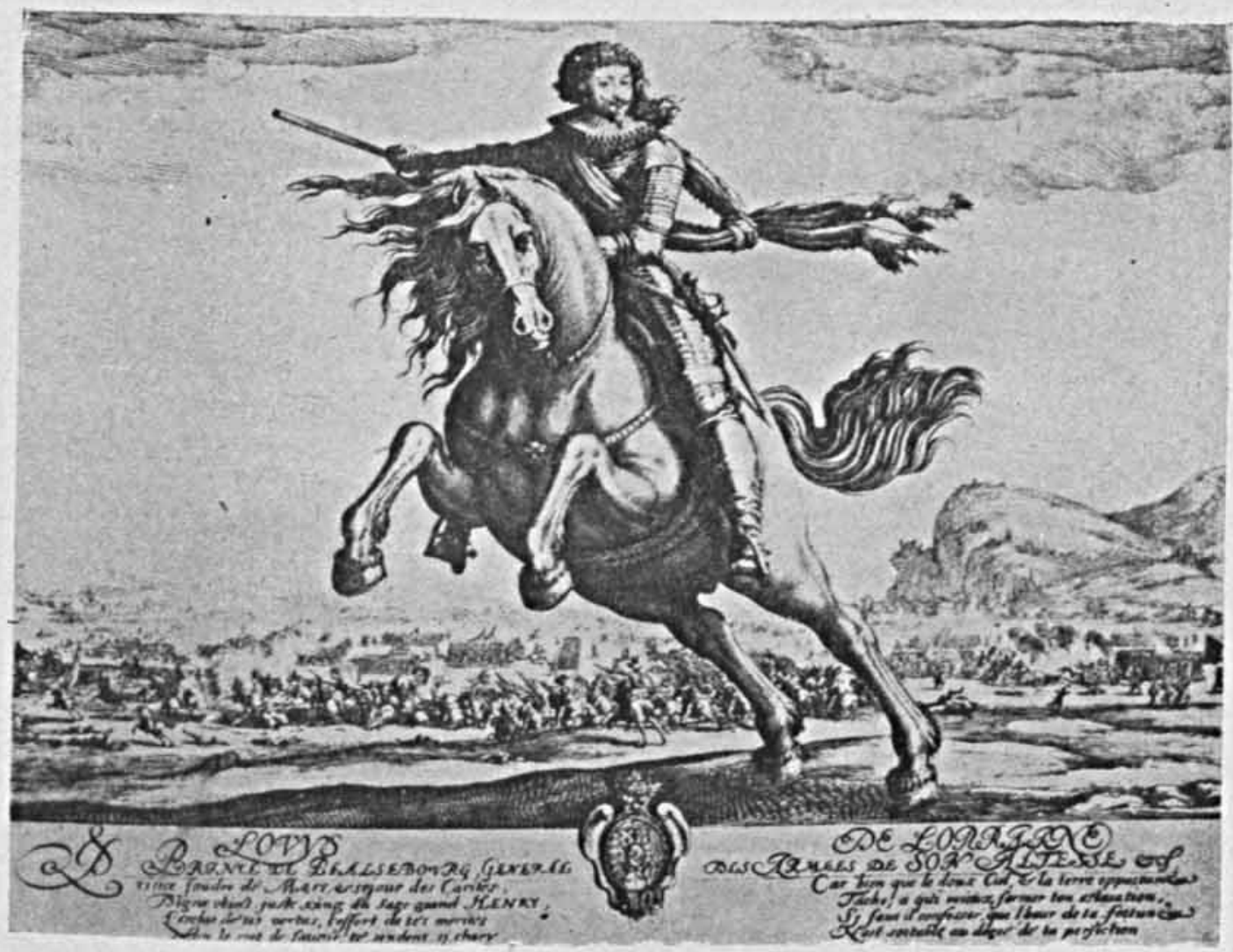

5. Callot.-Luis de Lorena, Principe de Phalsbourg. 


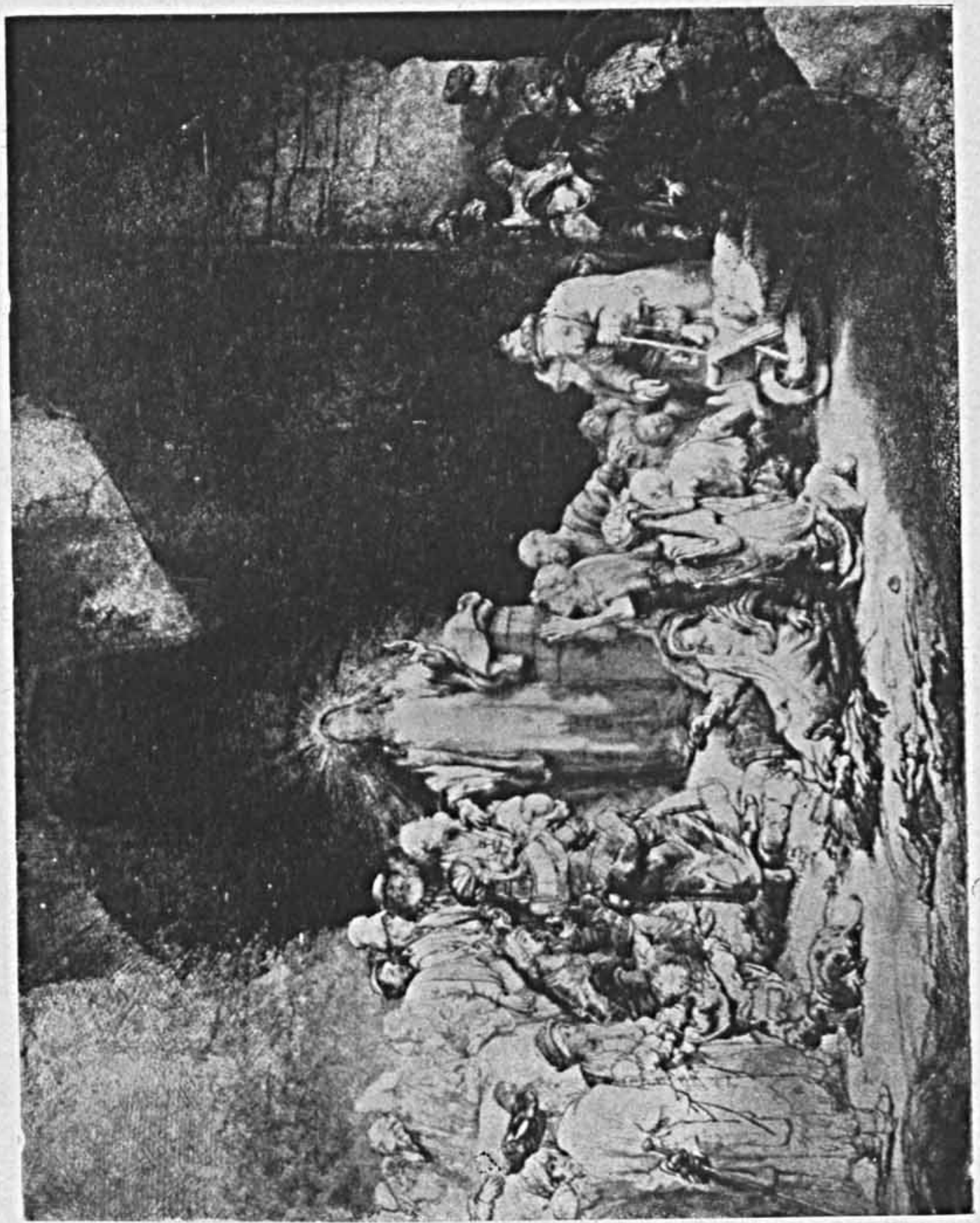




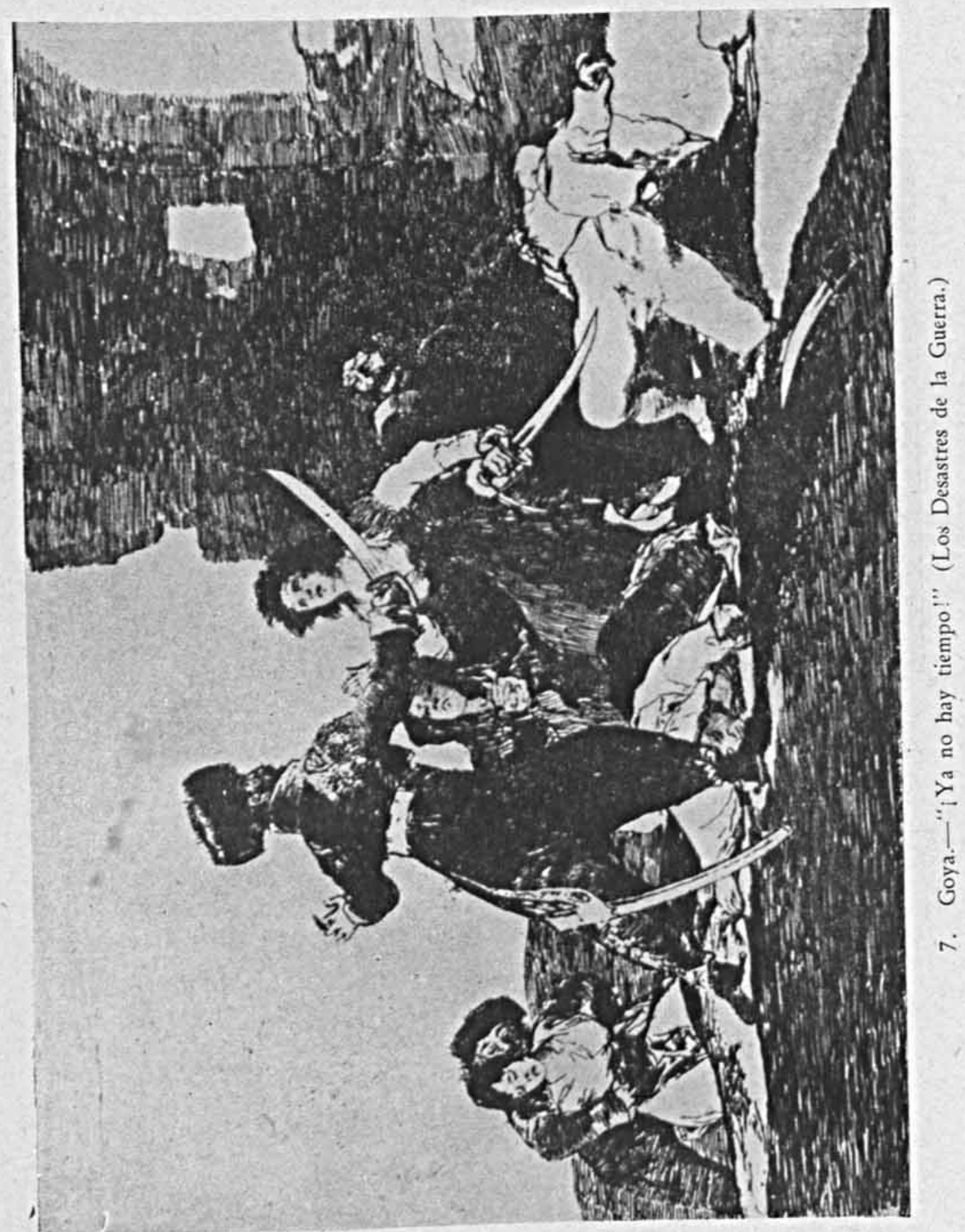


DOI: http://dx.doi.org/10.22201/iie.18703062e.1943.10.363

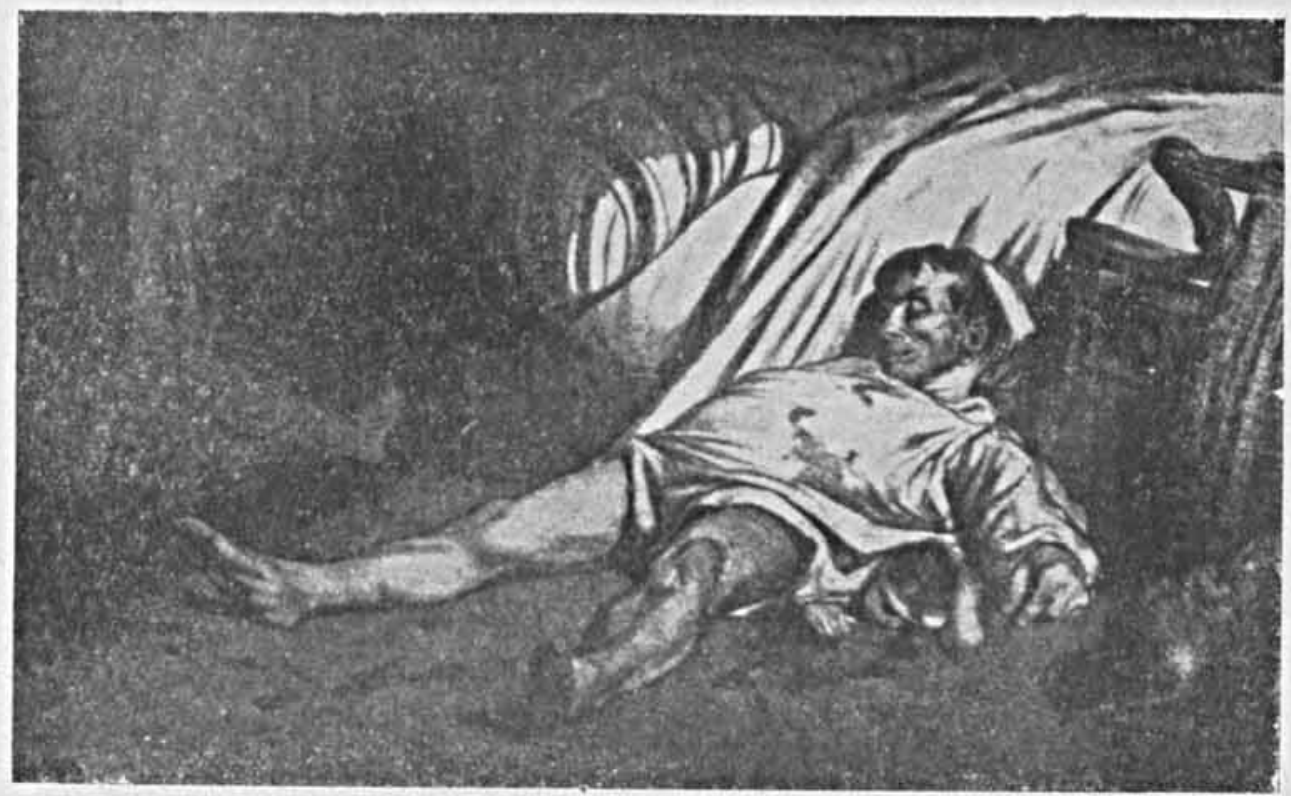

8. Daumier.-La Calle Transnonain. 
DOI: http://dx.doi.org/10.22201/iie.18703062e.1943.10.363

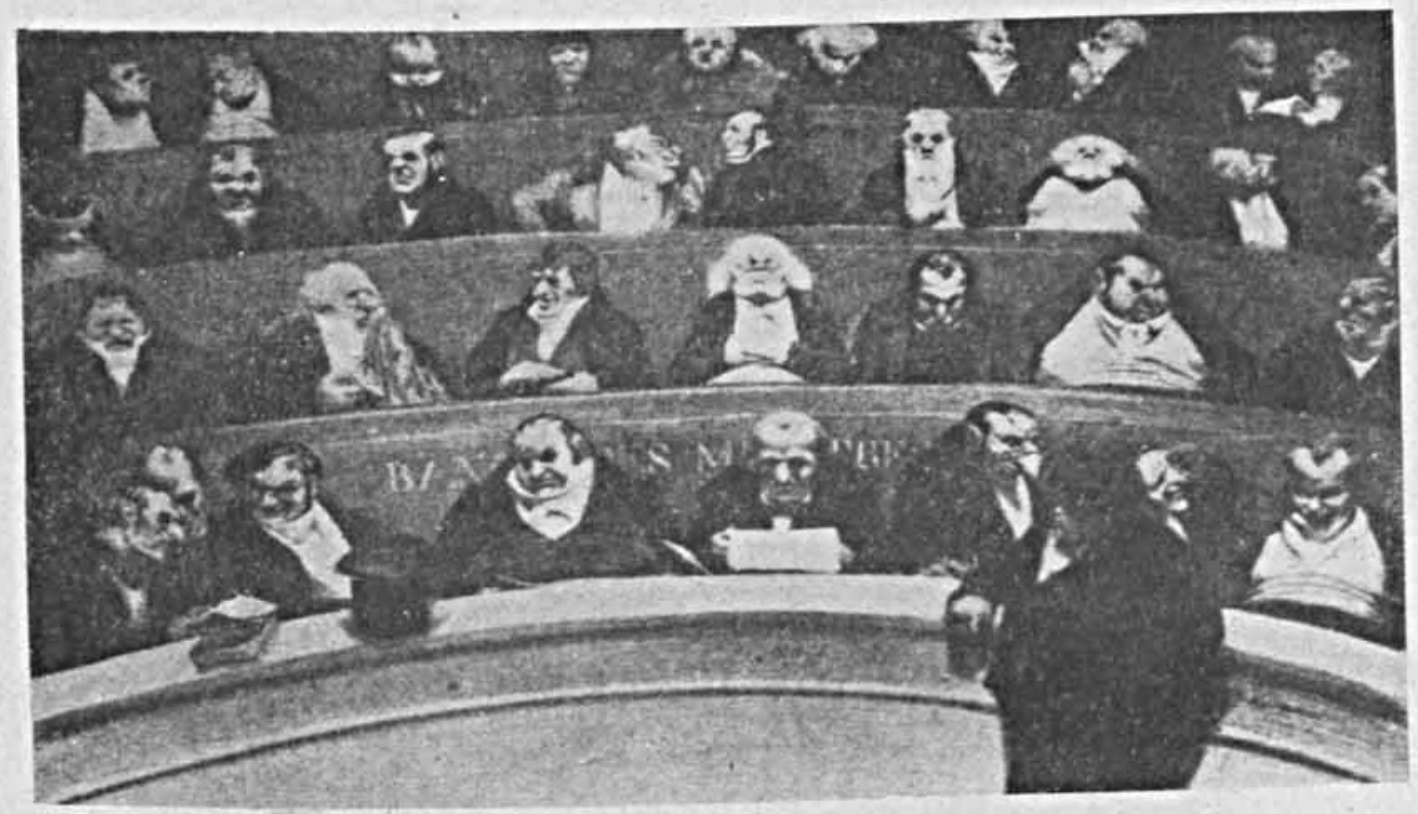

9. Daumier. - El Vientre Legislativo. 
DOI: http://dx.doi.org/10.22201/iie.18703062e.1943.10.363

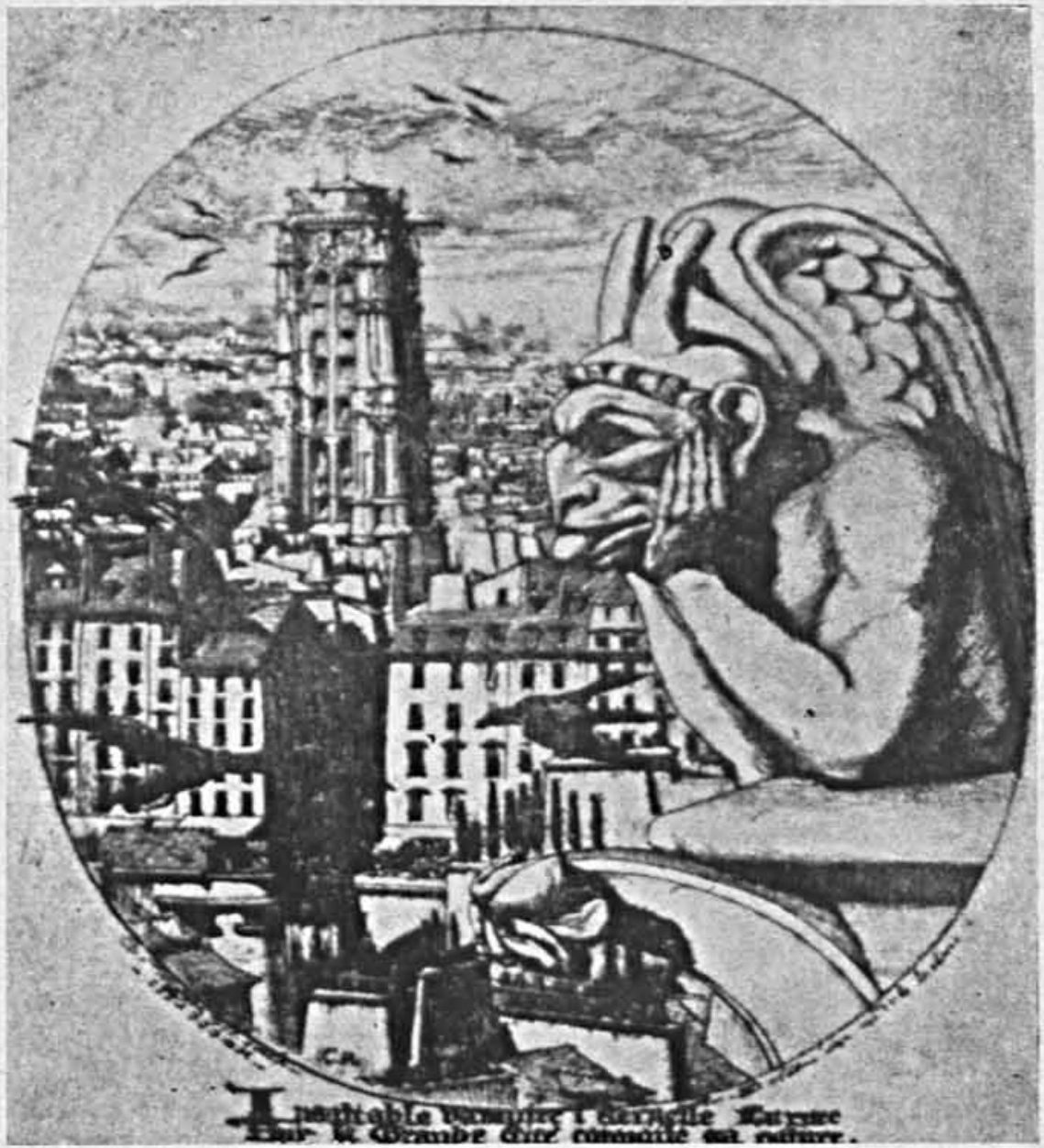

10. Meryon.-La Gárgola. 
DOI: http://dx.doi.org/10.22201/iie.18703062e.1943.10.363

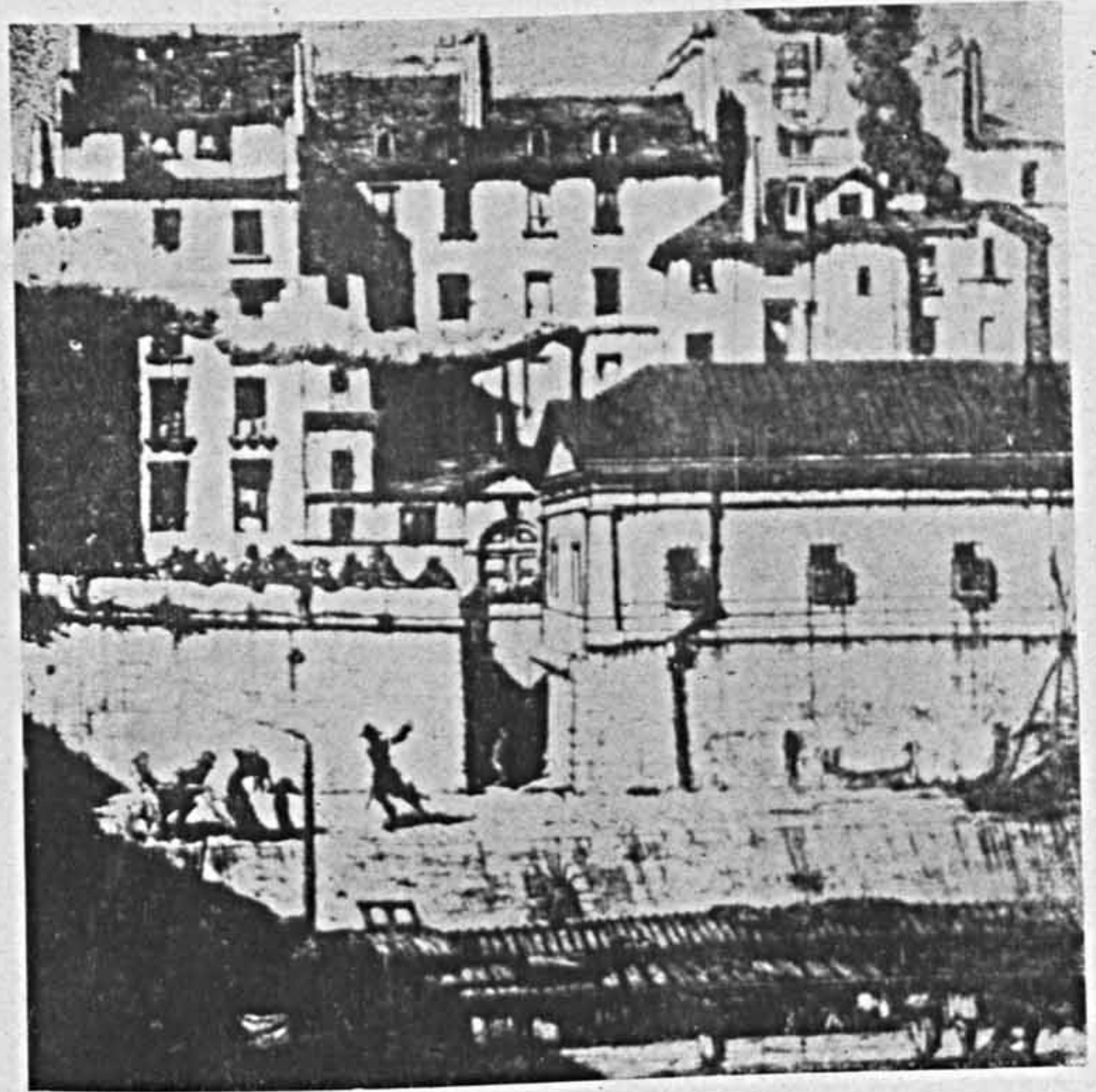

11. Meryon.-La Morgue. 
DOI: http://dx.doi.org/10.22201/iie.18703062e.1943.10.363

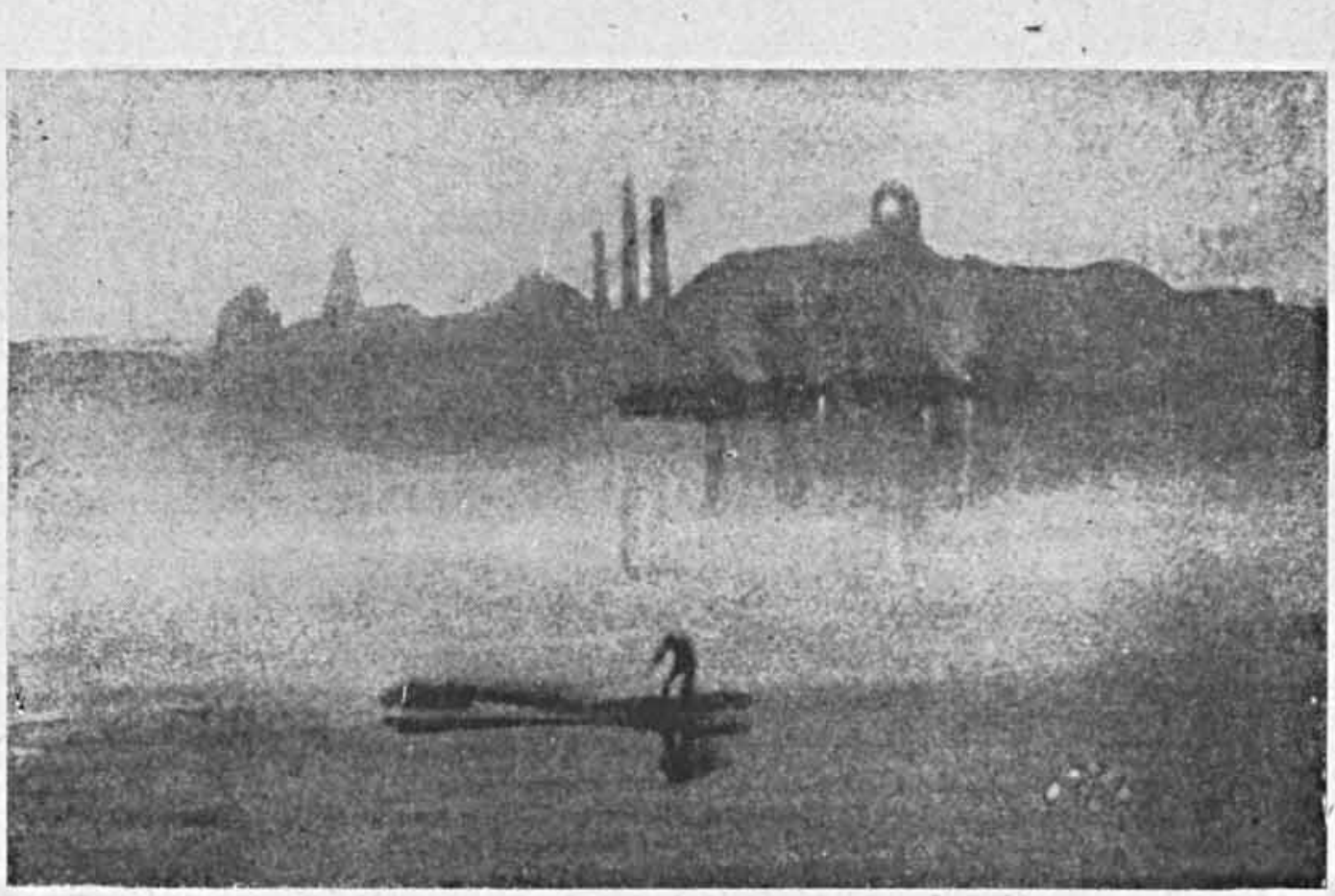

12. Whistler.-Nocturno. 
DOI: http://dx.doi.org/10.22201/iie.18703062e.1943.10.363

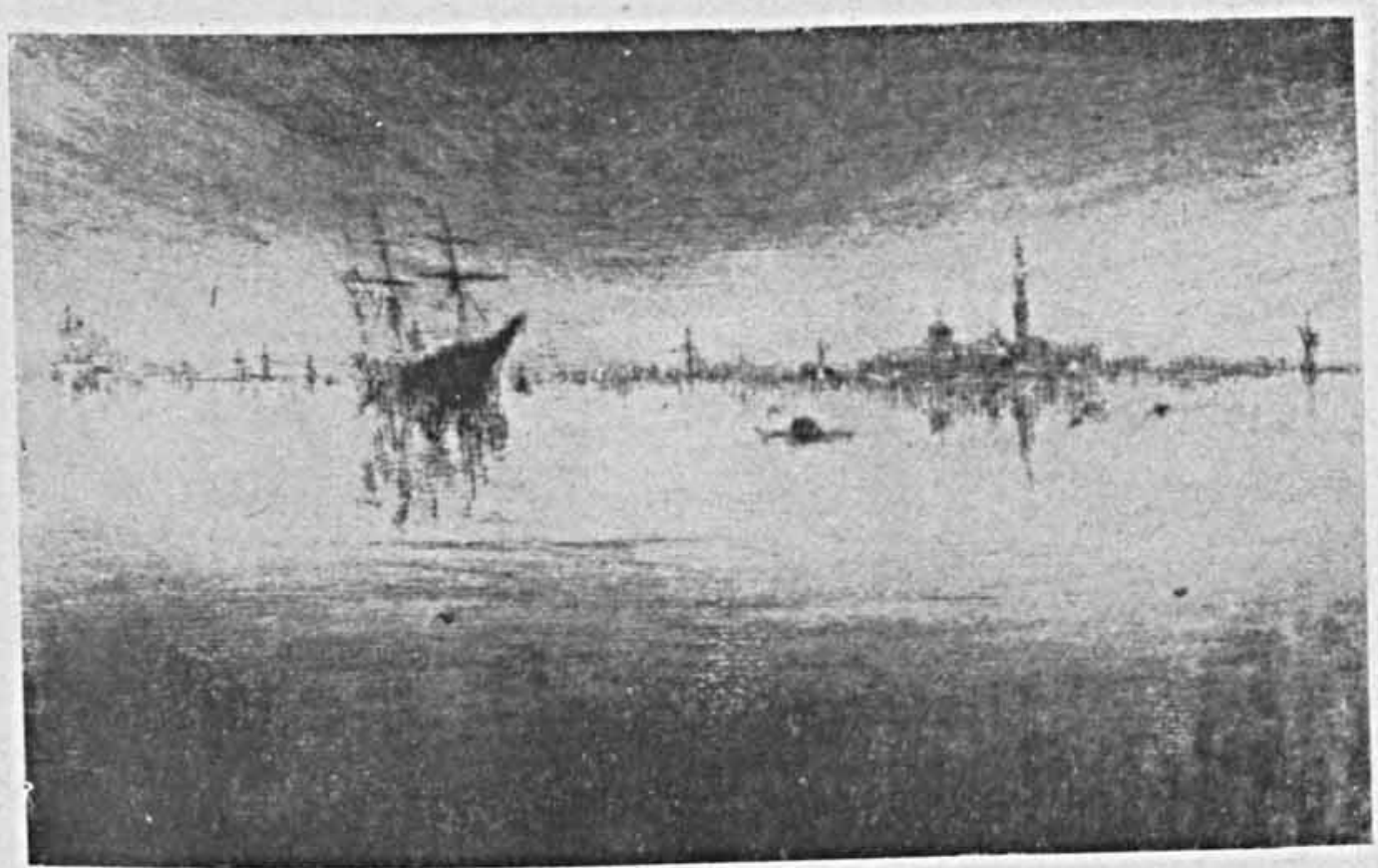

13. Whistler.-Nocturno.

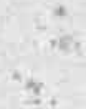




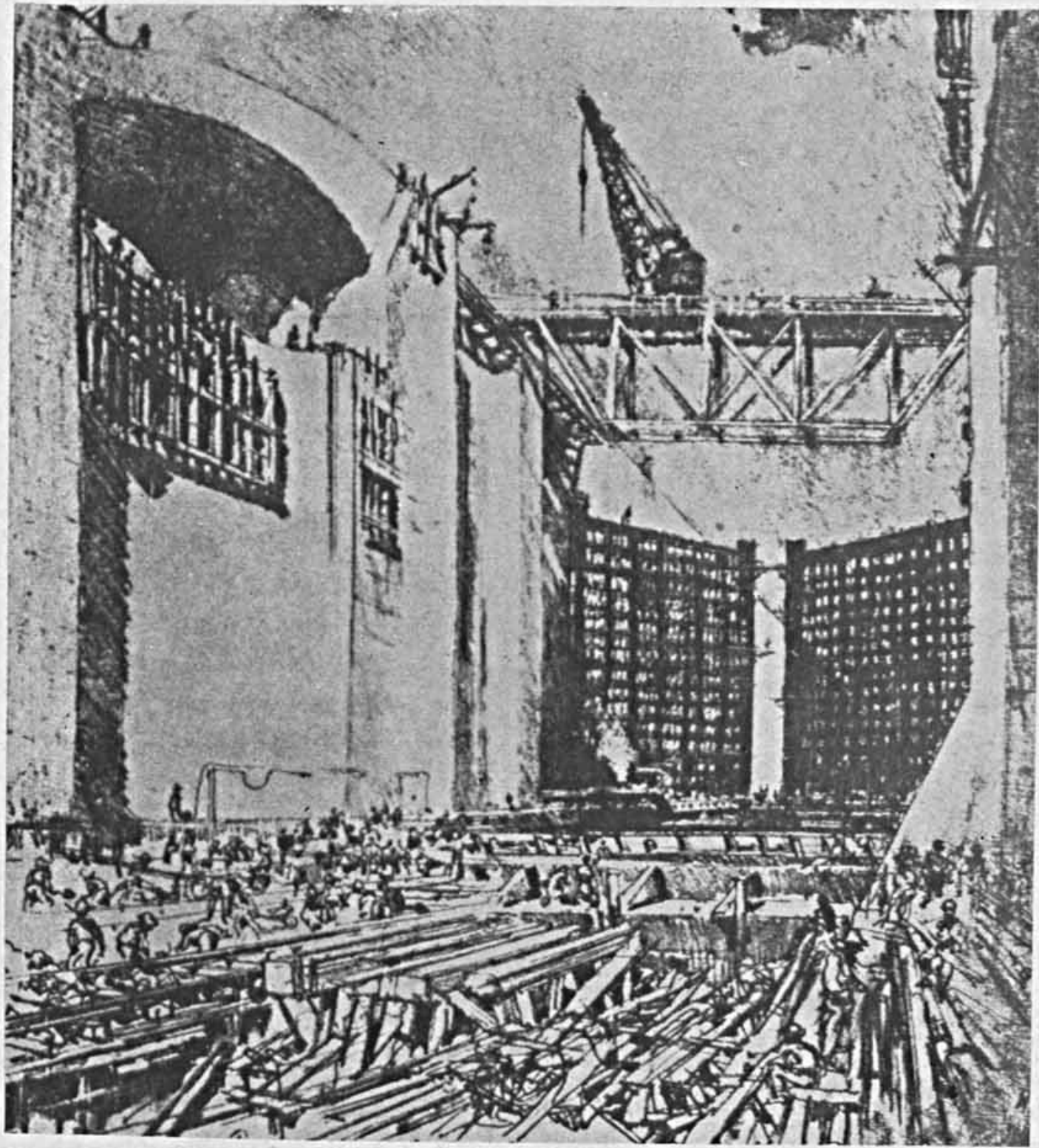

14. Pennell.-Exclusa de Pedro Miguel. (Panamá.) 